r9r. ABRAMSON, FRIEDMAN (1938), Am. J. Physiol., 123, I.

192. FRIEDMAN, ABRAMSON, MARX (I938), Am.J.Physiol., 124, 285.

193. KITZ and FRIEDBERG (1939), Am. J. Physiol., 127, 29.

I94. HILL and ANDRUS (1940), Proc. Soc. Exp. Biol. and Med.,44, 2 I 3.

195. PICKERING and PRINZMETAL (1940), J. Physiol., 98, 314.

I96. CORACON and PAGE (1939), Am. J. Physiol., 126, 354 .

I97. SMITH (r939), Porter Lectures, 9, University of Kansas.

198. STEELE and SCHROEDER (1939), J. Clin. Invest., 18, 477.

199. PENTL, PAGE, DAVIS (1943), J. Biol. Chem., 147, I43.

200. PAGE, SWAIN, KNAPP, ANDRUS (194I), Am. J. Physiol., 135,

20r. LELOIR, MUNOZ, TAQUINI, BRAUN-MENENDEZ, FASCIOLO (1942), Rev. Argentina cardiol., 9, 267.

202. HAYNES and DEXTER (I943), Federation Proc., 2, 20.

203. PAGE and HELMER (1940), J. Exp. Med., 71, 29.

204. CROXATTO and CROXATTO (1942), Science, $96,519$.

205. PRINZMETAL, ALLES, MARGOTAS, KAYLANDS, DAVIS (1942), Proc. Soc. Exp. Biol. and Med., 50, 288.

206. MUNOZ, BRAUN-MENENDEZ, FASCIOLO, LELOIR (1940), Compt. rend. Soc. Biol. 134, 487 .

207. TAYLOR and PAGE (1943), Am. J. Med. Sci., 66, 205.

208. BURIINGAME LONG, OGDEN (I942) Am, I Physiol. 137, 473. 209. BRAUN-MENENDEZ, FASCIOLO, LELEOIR, MUNOZ (I944), Rev. Soc. Argentina Biol., 16, 643.

210. ABELOUS and BARDIER (1908), J. Phys. et. Path. Gen.; 10, 627. 211. ABELOUS and BARDIER (1909), J. Phys. et Path. Gen., 11, 34.

212. ABELOUS and BARDIER (1908), Compt. rend. Soc. Biol., 65, 63 and 560 .

213. ABELOUS and BARDIER (1908), Compt. rend. Soc. Biol., 64, 906. 214. ABELOUS and BARDIER (19II), Compt. rend. Soc. Biol., 71, 62

215. FRETWURST and HERTZ (1932), Ztschr. f. klin. Med., 122, $64 \mathrm{I}$. 2I6. DINGERMANSE and FREUD (1933), Acta. brev. Neerland, 3, 49. 217. LOCKETT (1944), J. Physiol., 103, 185 .

218. VON EULER (1944), U.S. Acta Physiol., Scand., 7, 285

219. VON EULER (1944), U.S. Nature, 154, July, 17

220. LOCKETT (1944), J. Physiol., 103, 68.

221. LOCKETT (In the Press), J. Physiol.

222. GOLDBLATT (1940), Am. J. Clin. Path., 10, 40.

223. CORACON and PAGE (r94I), J.Am. Med. A ssoc., 116,690.

224. GOLDRING, CHASIS, RANGES, SMITH (194I), J.Clin. Invest., 20, 637 .

225. CHASIS and REDISH (r94I), J. Clin. Invest., 20, 655 .

226. FRIEDMAN, SELZER, ROSENBLUM (194I), J.A.M.A., 117, 92. 227. CANTOR (1942), Ann. Surg., 115, 400.

228. WEINSTEIN (1942), Surg. Gynaec. Obstetr., 74, 245.

229. TEITELBLUM (1942), Quart. Rev. Biol., 17, 135 .

230. MACFARLAND and DAVENPORT (I94I), J. Compt. Neurol.,

231. FOA, WOODS, PEET, FOA (1943), Arch.Int. Med., 71, 357.

232. BERTELS, PAPPEN, RICHARDS (1942), Ann. Int. Med., 17, 807.

233. PAULI (1903), Munchen med. Wchnschr, 4, 153.

234. (1943), Am. J. Med. Sci., 206, 668.

235. SCHREIBER (1925), Biochem. Ztschr, 163, $24 \mathrm{I}$.

236. GRIFFITH and LINDAUER (194I), Am. Heart J., 14, 710.

237. KOFFLER and FREIREICH (I044), Am. J.M

238. GOLDBLATT, KAHN, LEWIS (1942), J. Am. Med. Assoc., 119,

239. BARKER and DAVIS (1939). Ann. Surg., 110, ror6.

240. KUNZ, SHAPIRO, MILLS (1940), Am. J. Med. Sci., 202, 378.

24I. POTTER (I944), J.A.M.A., 124, 568.

\section{FRACTURES OF THE SPINE AND PELVIS}

By E. H. Hambly, F.R.C.S.

(Surgeon, E.M.S. Royal National Orthopaedic Hospital, W.I)

\section{FIRST-AID TREATMENT OF ALL FRACTURES OF THE SPINE}

The best treatment when a fracture of the spine is suspected is to leave the patient where he may be lying. He should not be moved unless absolutely necessary. Morphia should be administered to relieve pain and shock. The abdomen should be examined if possible before the administration of morphia, as the latter tends to mask any abdominal signs. The patient should be kept warm.

When the ambulance arrives the safest way to lift the patient is by the use of a strong pole and canvas slings around the head, neck, trunk, pelvis, $;$ and lower limbs. He should be carried in the $\underset{\propto}{\mathbb{Q}}$ position in which he is lying. No attempt eitherc. to flex or extend the spine should be made until $\overrightarrow{\vec{F}}$ $\mathrm{X}$-ray examination has been made.

\section{FRACTURES OF THE CERVICAL SPINE FRACTURES OF THE ATLAS}

Clinically, fracture of the atlas is shown by气 spasm of the cervical muscles. The head is held forwards in a characteristic manner as if it is $\overrightarrow{0}$ tending to fall off. The same curious clinical ${ }_{-}^{\circ}$

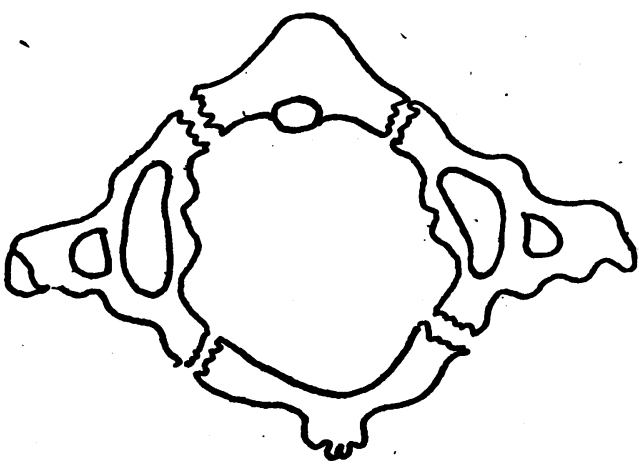

DiAgram 1.-Fractures of the atlas.

picture sometimes appears with active tuberculo i⿱宀 of the cervical spine. The position of the fracture is shown in Diagram I.

If fracture of the atlas is associated with paralysiso of the limbs due to pressure on the cord skullo traction should be applied for several weeks. This is described later. Otherwise, the head and neck are immobilised for three months in plaster.

\section{DISLOCATION OF THE ATLAS}

This is due to tearing of the transverse ligamento of the odontoid process. There is great risk of the odontoid process pressing backwards on the spinalo cord with resulting paralysis, and even death: Thus treatment consists in reducing the dislocation?

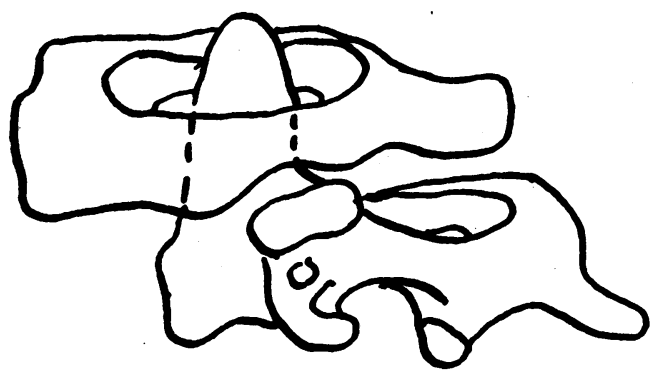

DIAGRAM 3.-Dislocation of atlas due to tearing of trans- $\square$ verse ligaments of odontoid process. 
under anaesthesia and in applying a plaster spica in full extension for three months. The writer has recently had a case of old un-reduced dislocation of the atlas. This presented a gross rotation deformity, which was impossible to reduce by prolonged traction. If $\mathrm{X}$-rays of such a case show a tendency to progressive dislocation, or if secondary paraplegia appears, spinal fusion must be undertaken. See Diagram 2.

\section{SO-CALLED HYPERAEMIC SPONTANEOUS DISLOCATION OF THE ATLAS ON THE ODONTOID}

It is often quoted that tonsilitis or tuberculous infection of the cervical glands causes softening and stretching of the transverse ligaments of the odontoid process with the same dislocation as described above. The writer is inclined to agree with Mr. H. A. T. Fairbank that this aetiology is unproven and indeed unlikely. A case recently seen by the writer, which had been treated for six months for functional torticollis, gave no history of sepsis nor injury. Could this condition be a congenital abnormality? Alternatively, is there an actual inflammatory lesion in the odontoid transverse ligaments? See X-ray No. I.

\section{HYPER-EXTENSION FRACTURE-DISLOCATION OF THE ATLAS AND THE AXIS}

The arches of the atlas and the axis can be fractured together in a hyper-extension injury. Treatment consists in reducing the fracture-

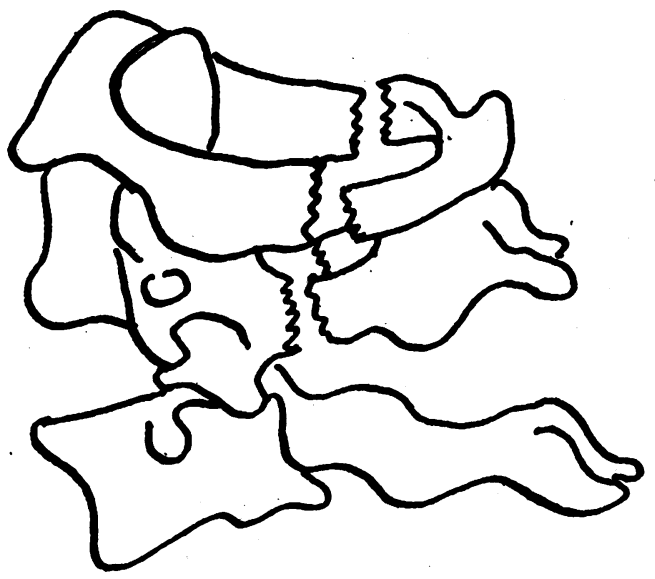

DiAgRAM 3.-Hyper-extension fracture dislocations of the atlas and axis.

dislocation under anaesthesia. If paraplegia is present a plaster should be applied in full flexion by the method devised by the writer. See Diagram No. 4. It will be found that a head plaster spica tends to form trophic pressure sores in the presence of paraplegia. The fixation of a short head spica to a hip spica tends to circumvent this complication. If there is no paraplegia, the head is plastered in full flexion in a plaster which extends down to the iliac crests. See Diagram No. 4.

\section{FRACTURES OF THE ODONTOID}

Fractures of the odontoid may be classified into three types. Firstly, fractures across the base with minimal displacement can be treated in a plaster spica or a leather collar for six weeks.

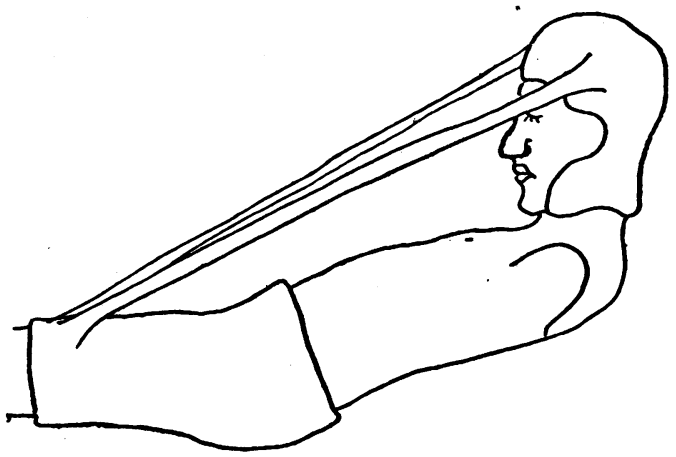

DiAgram 4.-Writer's method of immobilising hyperextension fracture-dislocations of the atlas and axis, and fracture-dislocations of the odontoid process.

The second type consists of a flexion fracturedislocation, which carries the atlas with it. There is less risk of death in this injury than when the odontoid process is not fractured as in Diagram 2. Treatment consists in reduction under anaesthesia, and the application of a plaster spica in full extension if there is no paralysis. If paraplegia is present the plaster devised by the writer as in

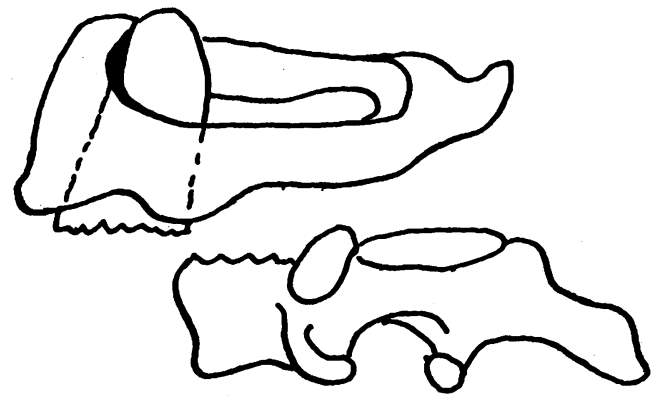

Diagram 5.-Flexion fracture-dislocation of odontoid carrying the atlas.

Diagram 4 is suggested as a full spica produces trophic ulceration. This type of injury is shown in Diagram No. 5 and X-ray No. 2.

The third type of odontoid fracture is the hyperextension fracture-dislocation of the odontoid process carrying the atlas with it. These are 
reduced under anaesthesia and plastered in full flexion in a full head spica. If paraplegia or quadriplegia is present, the hip-head spica shown in Diagram 2 is suggested. This was recently used by the writer in such a case of hyper-extension fracture-dislocation of the odontoid. The patient did very well, but unfortunately died after four months from a severe duodenal ulcer and bronchopneumonia. He had discarded his plaster, and had been getting up for three weeks. The original head and thorax plaster spica had caused deep trophic ulceration associated with quadriplegia. The hip-head spica was devised to take the pressure

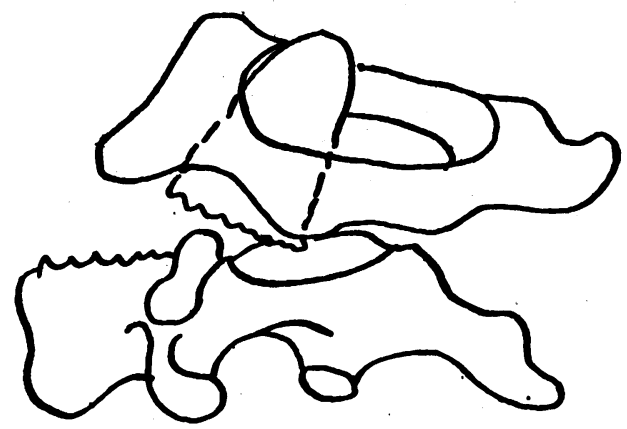

DiAgram 6.-Hyper-extension fracture-dislocation of odontoid carry the atlas.

off the scapulae and back. The management of fracture-dislocations of the spine with paraplegia is discussed later. See Diagram No. 6.

\section{FRACTURES AND SUBLUXATIONS OF THE OTHER CERVICAL VERTEBRAE}

(I) SPRAINS OF THE LATERAL INTER-ARTICULAR JOINTS.

A sprain of these joints is usually described by the patient as a severe "crick in the neck." It is associated with a sudden movement, e.g. when cleaning the teeth. There is spasm and considerable pain on one side of the neck. X-rays must be taken to exclude subluxation or dislocation. The normal X-rays of the neck show the articular surfaces of the lateral joints to be parallel. Such lateral X-rays should be taken in full flexion as extension may mask the subluxation. It must be pointed out, however, that some normal necks show a similar flexion angulation in the $\mathrm{X}$-rays when the cervical spine is fully flexed.

The best treatment for such a sprain is to apply several elastoplast bandages over the trapezius of the affected side. This gives the patient confidence and relieves the pain and spasm, which usually passes off in a few days. If it does not do so, a manipulation of the cervical spine relieves the condition.
(2) SUBLUXATIONS OF THE LATERAL INTER-⿳亠丷⿵冂丶⿵冂丶 ARTICULAR JOINTS.

This is a common injury, and can be associated ${ }_{\circ}^{\mathbb{\Phi}}$ with minor twisting injuries. Lateral $\mathrm{X}$-rays.. with the cervical spine flexed show the upper vertebral body sliding forward on the one below. There is also a narrowing of the intervertebral disco anteriorly. See Diagram No. 7.

Treatment of a subluxation of the cervical inter-s articular joints is carried out by applying a head® spica in full extension. This is done by placinge the patient on his back on a table with the head $\overrightarrow{ }$

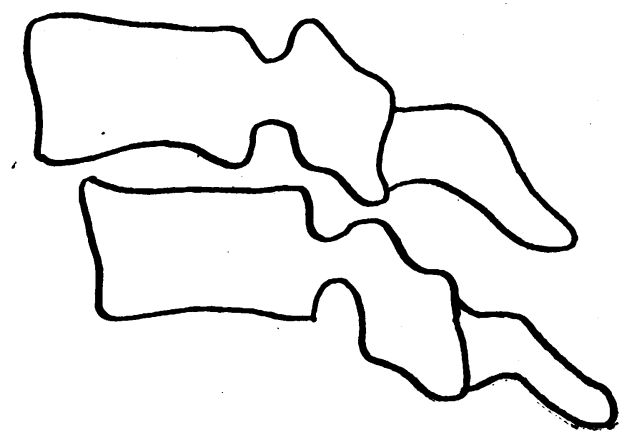

DIAGRAM 7.-Subluxation of lateral inter-articular joint of cervical spine.

hanging over the end of a wooden board fixed the table, and which reaches to the base of the neck. An alternative method of treatment is bys manipulation under anaesthesia. In many casesthis is satisfactory without further treatment.

(3) CRUSH FRACTURE OF CERVICAL VERTEBRAE. $\frac{\mathbb{2}}{\vec{\nabla}}$

A crush fracture of the cervical vertebrae 3 without dislocation is treated in a plaster spica with the head in hyper-extension. The plaster extends from the pelvis to include the head, ando extends forward to enclose the forehead.

(4) DISLOCATION AND FRACTURE-DISLOCATION OF .THE CERVICAL VERTEBRAE.

In these injuries there is a forward dislocation of both articular processes. Paralysis, due to pressure of bone or haematoma upon the cord, is commonly associated with this type of dislocation.

Treatment consists of strong traction withN stainless steel skull calipers. These are inserted under local anaesthesia, with the patient in bed. N A small hole is cut with a trephine through thec outer table of bone only. The holes should be made in a vertical line through the externake auditory meatus above the temporal line. $A \Phi$ weight of fifteen to twenty pounds is applied with? the head of the bed tilted. X-rays are taken every뭉 

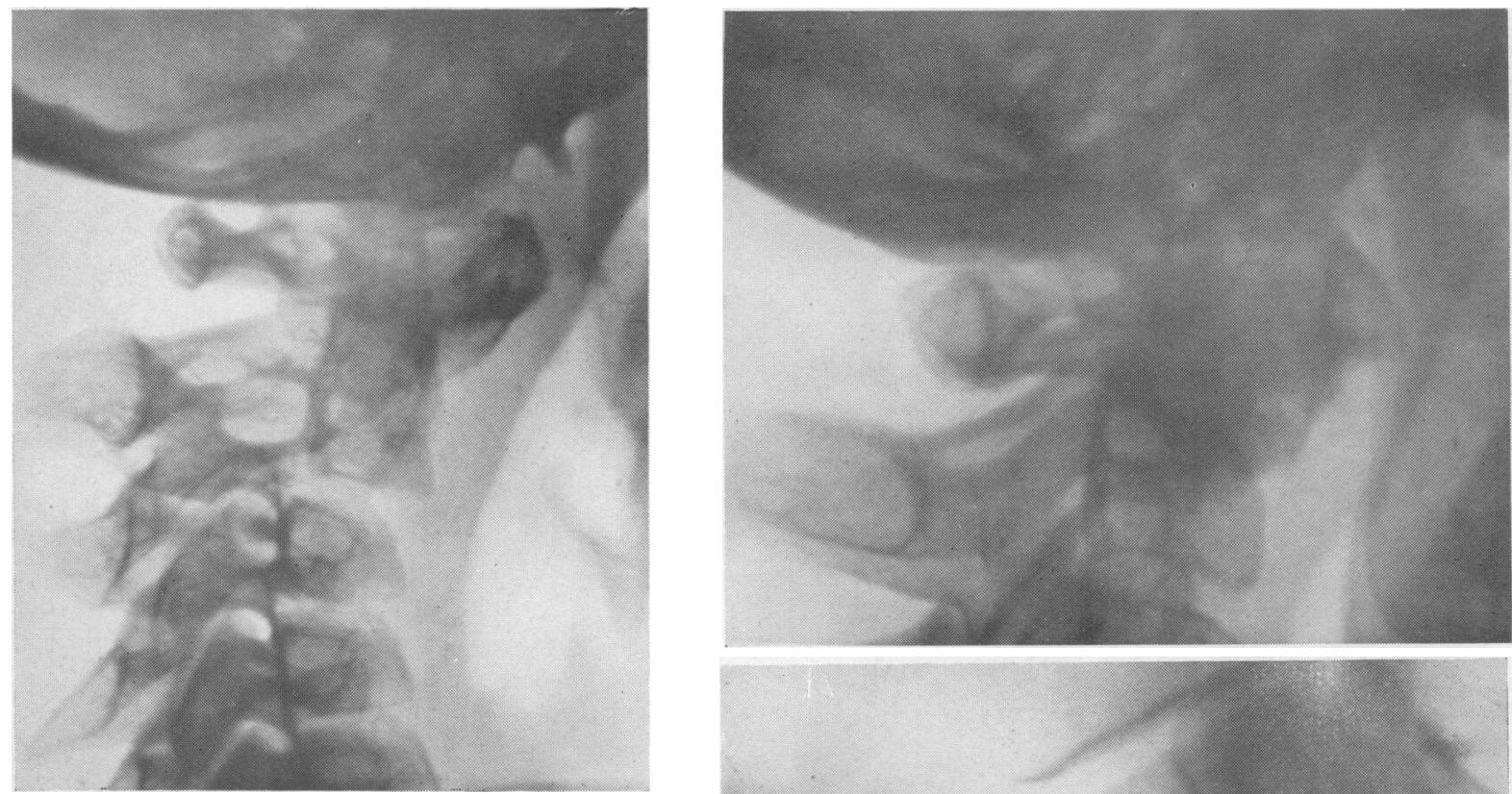

I.-Subluxation of atlas upon odontoid. Is this really due to hyperaemia? This is probably due to a congenital abnormality or to an infective lesion in the transverse ligaments.

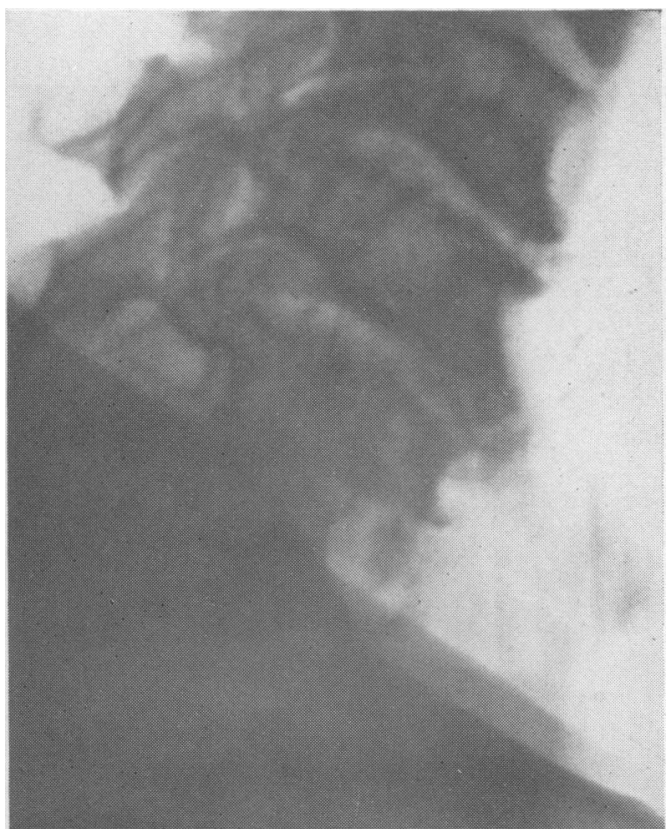

2. (Top right.)-Flexion fracture-dislocation of odontoid.

3. (Above.)-Fracture-dislocation of lower cervical spine. Quadriplegia and death set in as a result of treatment. Hyper-extension should not be applied in these cases without traction first. Preferably the patient should be immobilised without reduction.

4. (Centre right.)-Old comminuted fracture of the body of first lumbar vertebra, with osteo-arthritis.

5. (Bottom right.)-Maximum fracture-dislocation of dorsi-lumbar spine with paraplegia, which recovered completely after six months. X-ray shows tibial bone graft.

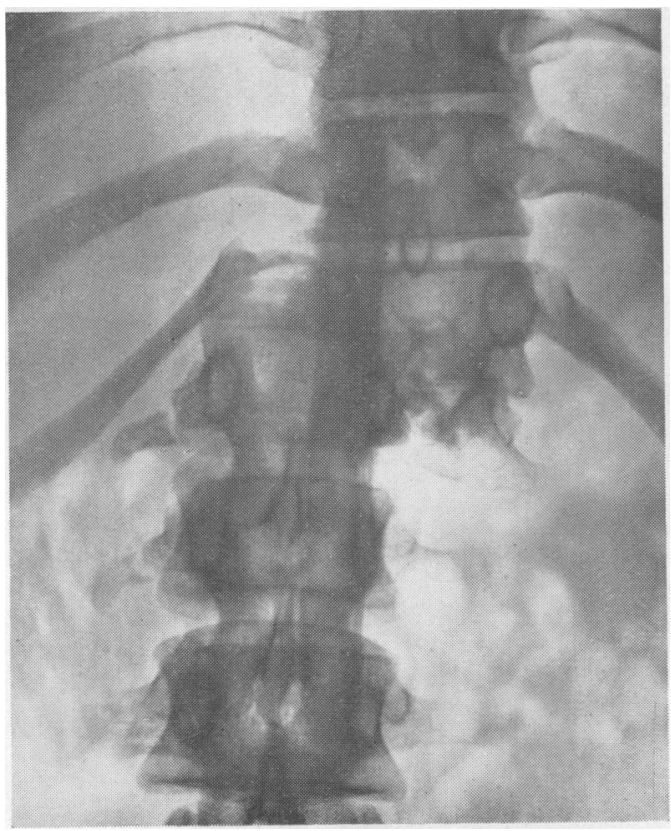


6. (Above.)-Lateral view of X-ray No. 5. Fracture-dislocation of thoraco-dorsal spine associated with fractures of the transverse processes of upper three lumbar vertebrae and of the twelfth rib.

8. (Below) Fracture-dislocation of the pelvis, with double fractures of the pubic bone and sacro-iliac dislocation on the same side. There was an associated lumbosacral dislocation with temporary canda equina involvement.

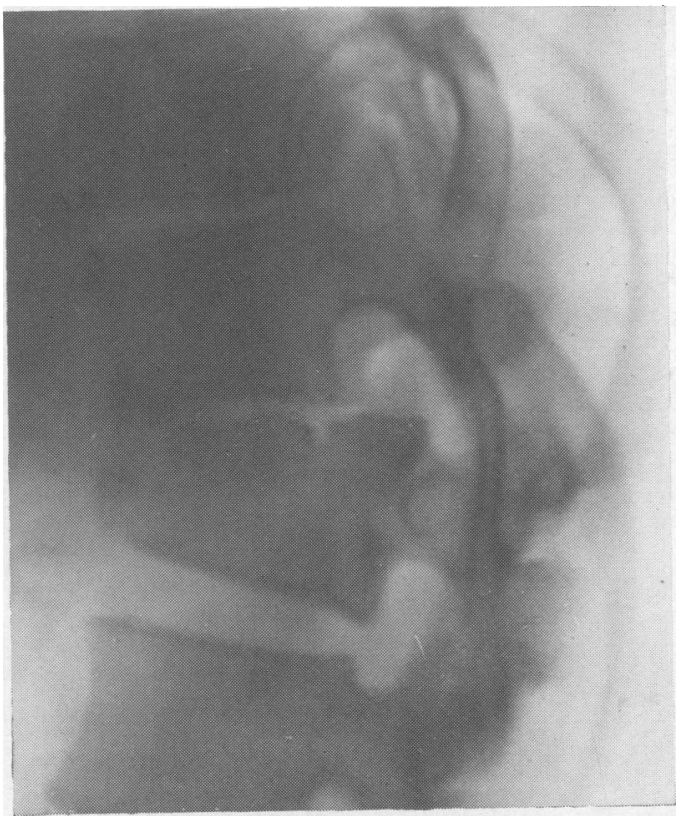

7. (Above)-Fractures of dori vertebrae four and five due to electro-shock therapy.

9. (Centre.)-Fracture-dislocatiof of dorsi-lumbar spine with par plegia. Open operation revealed a transverse traumatic henit laminectomy.

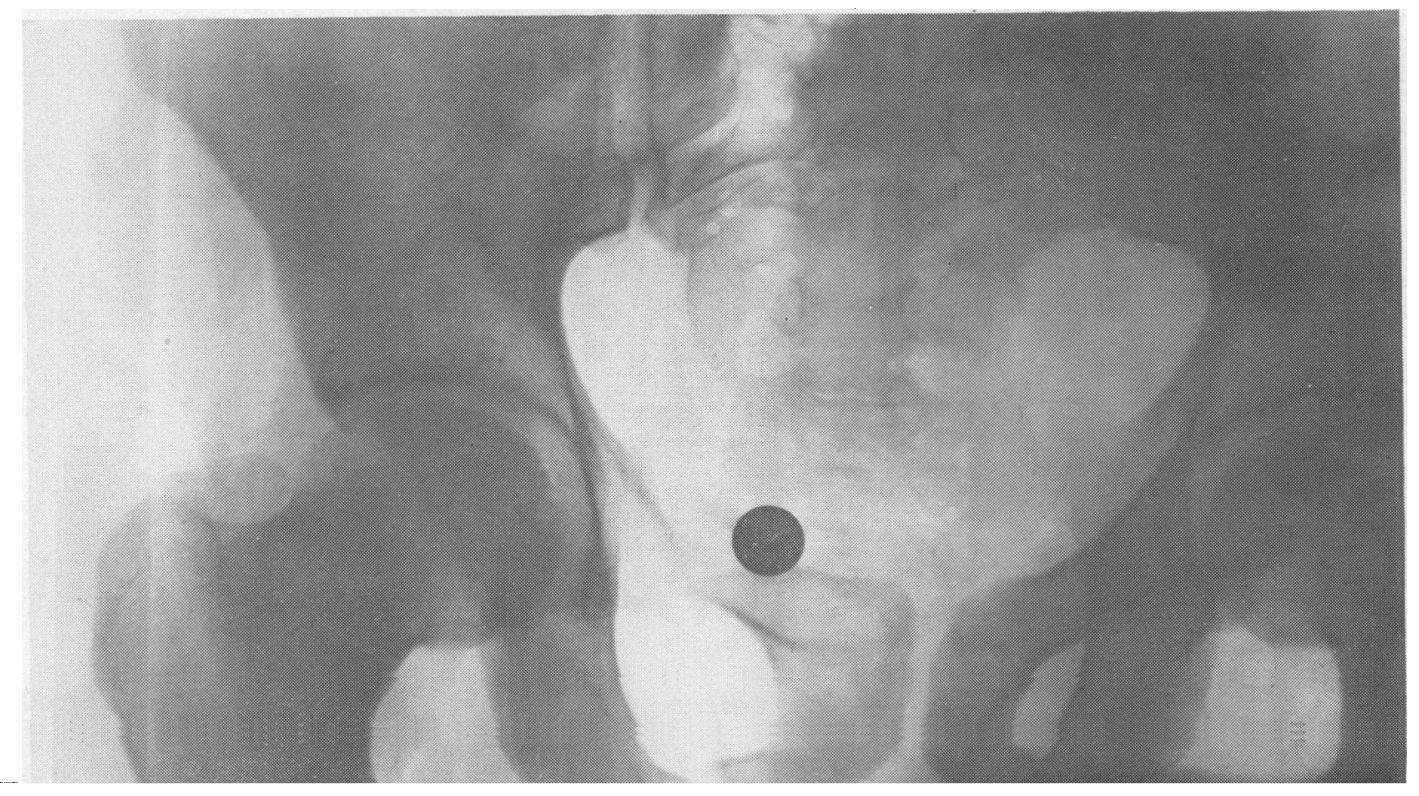


quarter of an hour. The crossbar carrying the pulley is then lowered when sufficient extension has reduced the dislocation. Lowering of the crossbar extends the spine. When reduction is fully effected, the traction is reduced to ten pounds. After four weeks a plaster spica is applied. This is the only method by which reduction of the dislocation can be effected. Even then it can be very difficult. Facetectomy may be necessary on one side. The treatment of paraplagia, which is so often associated with this injury, is discussed later. See Diagram No. 8 and X-rays Nos. 3.

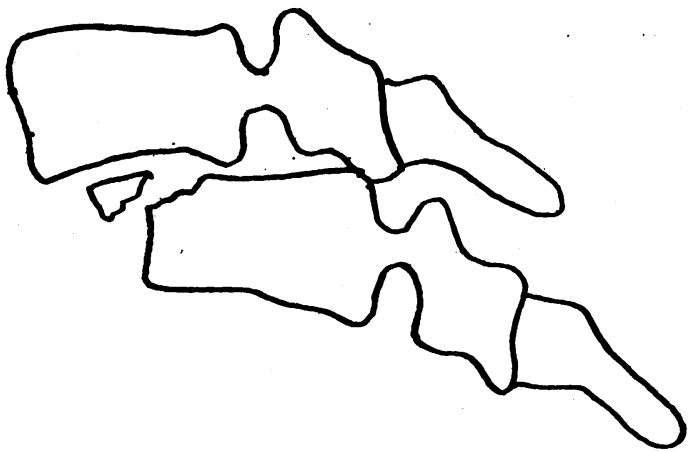

Diagram 8.-Fracture-dislocation of cervical spine.

\section{FRACTURES OF THE THORACIC AND LUMBAR SPINE}

\section{(I) WEDGE OR COMPRESSION FRACTURES.}

This is the commonest type of spinal injury, and is associated with falls from a height. Treatment of this injury consists in its reduction by hyper-extension and immobilisation in a plaster jacket. This is effected by a preliminary injection of Omnopon or morphia. The patient is then suspended with the legs on one table and the arms on a higher one. Alternatively, pulleys under the axillae give even more room for the application of the upper part of the plaster. This method was devised by $\mathrm{Mr}$. Watson-Jones. It is important to have the upper table clear of the chest, and the lower table to the upper thigh. Stockinette is put on beforehand, and adhesive felt over the iliac spines and over the kyphos. A plaster jacket is then applied as the wedging of the fracture corrects itself with the weight of the body. The plaster jacket is made by placing two plaster slabs on either side of the mid-line in front and behind. Three circular slabs are then applied around the patient at the levels of the manubrium sterni, the umbilicus, and the pubis. It is essential to have the plaster covering the sternum above and the pubis below. It is not necessary to cut an abdominal window except in emphysematous patients or in those who develop excessive flatu- lence or vomiting. These complications are usually relieved by getting the patient up. The axillae and groins are trimmed to allow free movements of the limbs. See Diagram No. 9.

Following the application of the plaster jacket an X-ray must be taken. If the wedging of the vertebra is not fully corrected a new plaster must be applied after a few days. It may also require

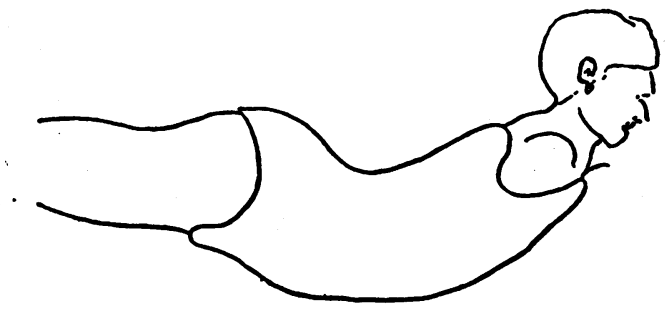

Diagram 9.-Plaster jacket for compression fracture of dorsal and lumbar vertebrae.

changing after a month. The plaster jacket is kept on for four months. After this time no spinal support is required. It cannot be overemphasised that extension exercises to the spinal muscles must be commenced immediately the jacket is applied. These exercises are further continued after removal of the plaster jacket until full movements are attained.

\section{(2) COMMINUTED FRACTURES OF THE THORACIC AND LUMBAR SPINE.}

This type of injury is due to a heavy weight falling on to the shoulders when in the stooping position, e.g. in coal mining. See Diagram No. Io and $\mathrm{X}$-ray No. 4. The inter-vertebral discs are fre-

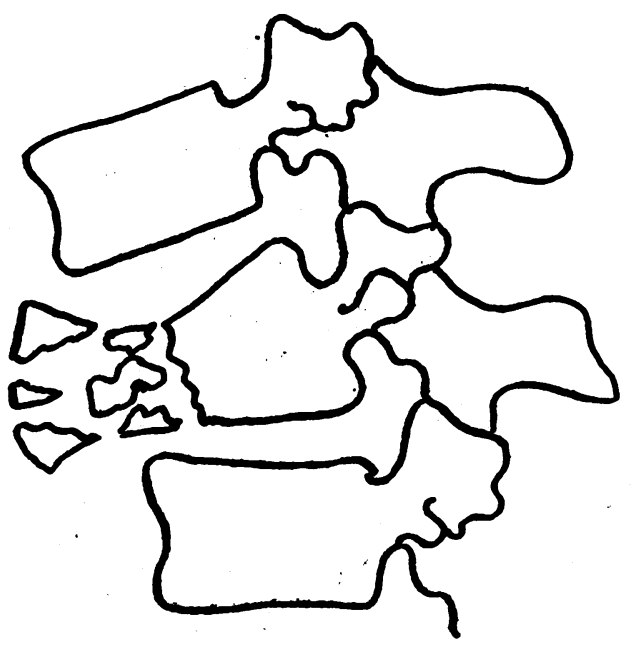

DIAGRAM 10.-Comminuted fracture of thoracic and lumbar spine. 
quently damaged in this fracture, and union is slower than in wedge compression fractures. If some of the fragments are driven posteriorly paraplegia may occur. This particular type of injury should therefore not be treated in hyper-extension. When, however, there is a comminuted fracture without displacement of bone into the inter-vertebral canal treatment is identical to that for a wedge compression fracture, namely, reduction and plaster in extension. In these cases pain is a common and prolonged symptom. It is best avoided by early grafting from the tibia. Extension exercises are commenced from the time of injury.

\section{(3) FRACTURE-DISLOCATION OF THE THORACIC AND LUMBAR SPINE.}

This is due to a flexion injury associated with a transverse momentum, e.g. in a car accident or bomb injury. Apart from a fracture of the vertebral body there is an associated fracture or dislocation of the posterior inter-articular joints. If fractured, reduction can be effected by extension. If dislocated, however, extension is dangerous. Open operation may then be required. The superior articular process of the lower vertebra affected should be excised on the side towards

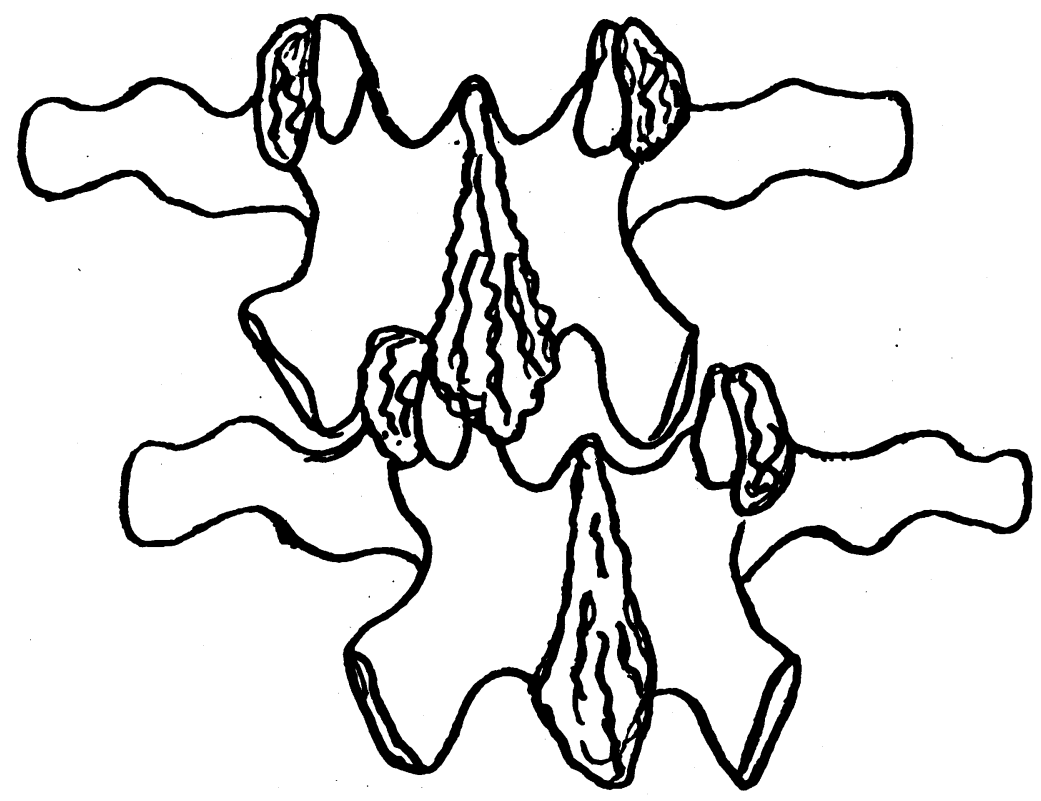

DIAGRAM II.-Fracture-dislocation of lumbar vertebrae. which the upper spine is dislocated. The vertebsa is then levered into position. The spine is thento treated in extension, usually in bed as paralysis ${ }^{\circ}$ is a common complication. See Diagram No. Paraplegia is due to the body of the vertebra below pressing on the lamina of the upper vertebra. See Diagram No. I2.

TREATMENT OF FRACTUREDISLOCATION OF THE SPINE WITH PARAPLEGIA

The four chief problems of these cases are:-

(I) The treatment of the bladder

(2) The general treatment of the patient for pain, trophic ulcer ation, etc. Although theo treatment of the patient is understood to come first in응 all methods of treatment, it is bladder sepsis which fre을 quently kills the patient.

(3) The primary treatment of the fractured spine. This in- 0 cludes the question of open $N$ operation and reduction of the fracture-dislocation.

(4) The later treatment of the fractured spine. This includes? the question of early or late bone-grafting. Also there iso 
the question of early or late attempts to get the completely paralysed patients ambulatory with splints and crutches.

The patient, whose spine is shown in X-rays Nos. 7 and 8 , was treated with complete recovery from the paraplegia and recovery from paralysis of the bladder after six months with the following principles of treatment:-

(I) In all cases of paralysis the bladder should not be catheterised. If there is paralysis of the bladder with associated paralysis of the limbs, supra-pubic-cystostomy should be undertaken within thirty-six hours. If there is bladder paralysis without paralysis of the limbs as there was in the case of fracture-dislocation of the lumbo-sacral joint, shown in X-ray No. 8 , the bladder may be catheterised.

(2) The fracture-dislocation rarely requires immediate operative reduction in actual practice. The cord is damaged at the time of the injury in many cases. In other cases, upon whom immediate reduction has been performed, the results have been depressing. Nevertheless, if it is suspected that open reduction or laminectomy is indicated, it should certainly be performed as soon as possible, bearing in mind the general state of the patient, who is usually shocked. Local anaesthesia is preferred by some surgeons, but gas, oxygen and ether is not contra-indicated. Reduction is effected by removal of the superior process of the vertebra below on the side towards which the upper segment of the spine is dislocated.

(3) Some cases have considerable pain. This is best minimised on a plaster bed. Trophic sores are also a major complication in these cases. For this reason plaster beds have been abandoned in favour of sorbo rubber mattresses. These, however, do not prevent trophic ulceration, and, in fact, the constant turning of the patient two or four hourly, which is done in order to relieve the pressure points, causes considerable pain, and must do damage to the fracture-dislocation.

The best method, in the writer's opinion, is to place the patient after supra-pubic cystostomy in an anterior plaster bed, which is made in the theatre immediately after the latter operation. The plaster bed is blocked in the theatre, and thus the patient returns to the ward in it. In order to reduce pressure sores, an anterior plaster bed or shell is made with the result that the patient can be turned when required without damage to the fracture-dislocation or pain. An anterior plaster bed has the merit that it aids supra-pubic drainage, and also enables wounds of the back to be dressed.

(4) Every attempt should be made, in the writer's opinion, to get the patient ambulatory within three months. Thus, if complete paralysis is evident, duralumin splints to the pelvis should be in use within three months from the injury. If partial recovery or almost complete recovery is evident, early bone grafting from the tibia should be undertaken to render the spine mechanically strong and to prevent residual pain. In the completely paralysed cases the patients should be given wheeled chairs and be encouraged to use them on the open roads. Grouping of the patients together all in one ward tends to make the patients depressed. They should be mixed up with patients who normally recover more quickly.

\section{FRACTURES OF THE SPINE WHICH SHOULD NOT BE TREATED IN HYPER-EXTENSION}

The following injuries of the spine should not be treated in hyper-extension.

(I) Fracture-dislocations of the Dorsi-lumbar spine before reduction of the dislocation.

(2) Comminuted fractures of the posterior wall of the vertebral body.

(3) Hyper-extension fracture of the spine, with fracture of the neural arch or vertebral body. This type of injury is rare.

(4) Traumatic Spondylo-listhesis. This is even rarer as the condition is usually congenital in origin. In the latter case there is failure of fusion between the neural arch and the vertebral body of the fifth or fourth lumbar vertebra at the base of the pedicle. The writer has recently recorded a case of Reverse Spondylo-listhesis, in which the fourth lumbar vertebra slipped down behind the fifth lumbar vertebra.

\section{OTHER FRACTURES OF THE SPINE}

\section{(I) HIGH FRACTURES OF THE DORSAL SPINE.}

Compression fractures of the upper dorsal vertebrae are both difficult to reduce and to immobilise. The best treatment for these fractures is extension exercises from the beginning with the patient in bed at first. Such a case is shown in X-ray No. 9. This shows a compression fracture of cervical vertebrae three, four and five. These are secondary to electro-shock-therapy for melancholia. He asked if he might get up after two weeks, and has had no pain after five weeks from the injury.

\section{(2) FRACTURES OF THE SPINOUS PROCESSES.}

This usually occurs in the spinous processes of the seventh cervical and first dorsal vertebra. It is known as "clay shoveller's" fracture. Bony union rarely occurs. Conservative treatment is usually successfúl, but excision is required if pain persists.

\section{(3) FRACTURE OF THE TRANSVERSE PROCESSES} OF THE LUMBAR SPINE.

This is a common injury. X-ray findings must be differentiated from congenital non-fusion of the 
transverse processes. Formerly, the injury was treated as a minor injury, but recently the extent of the injury has been if anything exaggerated. A good method of treatment is to put the patient to bed for two weeks. Extension exercises of the spine must be commenced from the first day.

\section{(4) FRACTURES OF THE SACRUM.}

This is also a common injury, but gross separation of the fragments is rare. Radiant heat should be given to relieve the pain, which is considerable. No other treatment is required.

\section{(5) FRACTURE OF THE COCCYX.}

This is frequently fractured or bruised, with subsequent adhesion formation. Persistent pain is common, and is known as coccydinia. This pain may also arise without injury. The best treatment for this condition, which is undoubtedly painful, is to allay the patient's anxiety, and by promising relief of pain in about six weeks. No physiotherapy should be prescribed, as it is very easy to make the patient neurotic. Soft cushions and liquid paraffin should be prescribed. Excision of the coccyx does not always relieve the pain. Manipulation of the sacro-coccygeal joint gives better results.

\section{FRACTURES OF THE PELVIS}

ISOLATED FRACTURES AND SUBLUXATIONS OF THE PELVIS.

Isolated injuries of the pelvis occur at four different sites, namely, the pubic rami, the sacroiliac joint, the symphysis pubis, and the ilium. Fractures of the pubic rami are common. If unassociated with other injuries, such as sacroiliac dislocation or bladder injury, the fracture may be ignored. It will unite whether the patient stays in bed or not. Rest in bed for two to four weeks relieves the pain.

It is strange how rarely the symphysis pubis is injured. Separation of the bones must be associated with an injury of the pelvic ring elsewhere, such as sacro-iliac subluxation or dislocation. This is confirmed by inspection of the back which will reveal prominence of the posterior superior iliac spine in these conditions.

Fractures of the ilium are best treated by rest, with the addition of radiant heat and active movements of the hip joints.

Sacro-iliac dislocation or subluxation is a major injury, as persistent pain and osteo-arthritis are common sequelae. Arthrodesis may be required later. The ilium is subluxated posteriorly towards the mid-line. This is reduced under anaesthesia and immobilised for three months. Minor degrees of sacro-iliac strain are treated with manipulation under anaesthesia with excellent results.
AVULSION FRACTURES OF THE PELVIS.

Fragments of the bone are avulsed by the 3 Sartorius muscle from the anterior superior spine, $\stackrel{\mathbb{Q}}{\square}$ the rectus femoris from the anterior inferior spine,.. and the hamstring muscles from the ischial tuber- $\overrightarrow{\vec{F}}$ osities. In all these cases the bone unites with conservative treatment.

\section{COMBINED INJURIES OF THE PELVIS.}

Combined injuries of the pelvic ring are of two main types which are due to two methods of injury. The first type is due to lateral compression. This $\vec{\circ}$ produces either a bilateral fracture of the pubic rami or a unilateral fracture of the pubic ramusc్ with a separation of the symphysis. As the injurys is due to lateral compression, the patient should be nursed on the back for four to six weeks. Lying on the side makes the injury if anything worse.

The second type of injury is due to anterolateral compression. These are severe injuries. The patient is shocked, and there may be an $\infty$ associated injury to the bladder or to the urethra. ${ }^{\infty}$ The fractured pubic rami and sacro-iliac dislocation? shown in X-ray No. Io was associated with $a_{\vec{O}}$ fracture-dislocation of the lumbo-sacral joint. There was partial paralysis of the lower limbs ando the bladder on the second day following the injury. This passed off on the fourth day. $ᄋ \overrightarrow{0}$

Sacro-iliac dislocation with fracture of the pu倩领 or separation of the symphysis are very diffictit to reduce fully. Many methods both of openo operation and reduction have been tried. In thes writer's opinion attempts at reduction by openo operation are contra-indicated as they fail to reduce the dislocation, and in the past have harmed the pelvic viscera. Traction on the limb $\overrightarrow{\vec{b}}$ on the side of the dislocation have similarly failedB to reduce the injury.

The best treatment appears to be to reduce the. dislocation under anaesthesia by placing theos patient on the side, as advocated by $\mathrm{Mr}$. R. Watson? Jones. The iliac crest is pushed forwards and? downwards. A double hip spica is applied and. traction maintained on the side of the dislocation with strapping fixed to a Thomas's splint incor porated in the plaster after cutting off the ring.

FRACTURE-DISLOCATION OF THE PELVIS WITH INJURY TO THE BLADDER OR URETHRA.

When the symphysis pubis is grossly separated the bladder may be torn almost in half anteriorly Immediate supra-pubic cystostomy is indicated with drainage of the cave of Retzius as wello This is more important than the treatment of thes fracture-dislocation. However, if an attempt is made to reduce the latter first healing of thẹ approximated bladder wound will be quicker. Reduction is carried out as described above wit 
the patient on his side. A double hip spica is applied with a window anteriorly large enough to accommodate the Hamilton Irving box.

The urethra may also be ruptured in association with a fracture-dislocation of the pelvis. An attempt should be made to reduce the dislocation at once under anaesthesia with the patient on his side. If this is successful, a catheter should be passed. If, however, reduction of the fracturedislocation is not effected, or, if the catheter will not pass following reduction an immediate suprapubic cystostomy is indicated. The writer has recently seen a fracture-dislocation of the pelvis with a damaged urethra in which the fatal black spot on the glans penis, due to gangrene, pronounced the fact that a supra-pubic cystostomy had been left until too late.

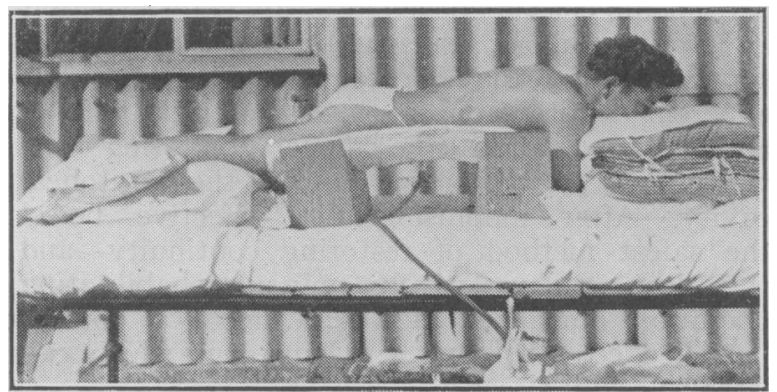

Author's method of treatment of fracture-dislocation of the spine, associated with paraplegia (see Text).

(Reproduced by kind permission of the "Medical Press and Circular.')

\section{CLOSURE OF COLOSTOMIES}

\section{By Major D. Lang Stevenson, F.R.C.S.}

Success in closure of colostomy and faecal fistula depends on a thorough investigation and preparation of the patient, with attention to every detail in operative technique and in post-operative treatment. The following article deals briefly with some general principles and describes a method of extraperitoneal closure of artificial openings in the bowel, which has given most satisfactory results.

\section{Preparation of the Patient}

In colon surgery it is important to bear in mind the different contents and function of the right and left tracts. As the right colon contains easily propelled fluid and is not subjected to the same tensions and trauma as the left, it can be treated surgically like small bowel. However, it would be disastrous to deal with the unprepared left colon in the same way, as faecal masses, gaseous distension, and the relatively poor blood supply of the bowel wall greatly endanger the suture line. It is therefore a first importance that the left colon is most carefully cleansed for a planned operation. This is achieved by a tap-water washout of the distal colon; in the morning from the colostomy and in the evening from the rectum. In some cases it may be a week or more before the returning fluid is clear. Scybalous masses can be softened by a slow continuous drip of warm water given by a catheter into the colostomy. If there is any tendency for the colostomy to be constipated, which is unusual, senna tea is given and the diet is suitably "modified. The day before operation a liquid non-residue diet is commenced and, for the first time, the proximal bowel is washed out with tap water. Two hours before operation both limbs of the colostomy are given a local cleansing with a half-pint of soapy water, all of which must be aspirated. The colostomy stoma is then irrigated with hydrogen peroxide followed by saline, and finally a plug of gauze soaked in flavine $\mathrm{r} / \mathrm{rooo}$ is tucked into the opening. After the skin has been thoroughly washed with soap and water for five minutes it is painted with flavine and spirit. On the theatre table the skin receives a further application of the same antiseptic.

- When constitutional effects are evident, general treatment in the form of a high protein and a high vitamin diet and fresh blood transfusions over a period of weeks, are invaluable. A course of Succinyl Sulphathiazole before an intraperitoneal operation, or where wound infection is perpetuated by a faecal fistula, is worth while in reducing the virulence of the bacterial flora. Four tablets five-times-a-day should be given three days before and three days after operation.

Any discharging sinuses at or near the site of a previous faecal fistula may be investigated by opaque media, and, if necessary, surgically explored; but on no account should an abdominal sinus of this nature be curetted or forcibly probed.

\section{Operation}

In the straightforward case the wounds are healed, a well-formed loop colostomy with no loss of bowel wall is present, and the distal gut is intact. Here, contrary to frequently expressed opinion, extraperitoneal repair gives uniformly good results if a sufficiently extensive mobilisation of the loop is carried out. This highly important part of the operation straightens out the temporary angulation or apparent spur in the bowel, allows the suture to be completed without tension, and restores the bowel to an unrestricted and good functional position. The word extraperitoneal is used in the sense that the loop of bowel is freed 